\title{
LEADERSHIP DEVELOPMENT, EMPOWERING LEADERSHIP DAN PERAN JOB SATISFACTION SEBAGAI VARIABEL MEDIASI DALAM UPAYA MENINGKATKAN ORGANIZATIONAL COMMITMENT
}

\author{
Maria Valeria Roellyanti \\ Sekolah Tinggi Teknologi Kedirgantaraan \\ ira.valerie@yahoo.com
}

\begin{abstract}
The study was aimed to examine the effect of Leadership Development and Empowering Leadership on the Organizational Commitment, that mediated by Job Satisfaction. Respodent of this study was taken from employees of Disperindagkop of Sleman Regency.
\end{abstract}

This study was conducted considering two factors of Leadership Development, i.e. coaching, training and development and four factors of Empowering Leadership, i.e. enhancing the meaningfulness of work, fostering participation in decision making, expressing confidence in high performance, providing autonomy from bureaucratic constraints. The Structural Equation Modeling (SEM) were used for developing theoretical and analyzing of this study..

Result of this study found that the two factors of Leadership Development and four factors of Empowering Leadership effected on Job Satisfaction, and than the correlation between Job Satisfaction and the organizational commitment was founded positive effect.

Development policies and programs in Disperindagkop should therefore focus on building Leadership Development and Empowering Leadership to make the hight Job Satisfaction and hight organizational commitment of it's employees.

Keywords: Leadership Development, Empowering Leadership, Job Satisfaction, Organizational Commitment, Structural Equation Modeling.

\section{PENDAHULUAN}

\subsection{Latar Belakang}

Menurut (Kriemadis \& Papaioannou, 2006), kita hidup di era globalisasi di bidang social, ekononi, budaya, dan juga lingkungan teknologi, dimana organisasi mampu meraih kesuksesan jika memiliki sumber daya yang mencukupi, antara lain adalah; bahan baku, fasilitas dan perlengkapan, dan juga yang sangat penting adalah sumber daya manusia. Terkait dengan pernyataan (Kriemadis \& Papaioannou, 2006) terutama yang menyangkut sumber daya manusia, maka kalangan praktisi semestinya memberikan perhatian serius bagi sumber daya manusis. Dalam masyarakat modern saat ini, persaingan dan pertumbuhan ekonomi yang cepat mempengaruhi perkembangan mental dan fisik karyawan di tempat kerja. Komitmen organisasi, tidak terlepas dari persepsi karyawan terhadap kepemimpinan. Kemudian perubahanperubahan yang mendasar dalam lingkungan bisnis telah menyebabkan pergeseran paradigm dan pentingnya manajemen sumber daya manusia dan fungsi-fungsinya. 
Departemen sumber daya manusia memegang peran penting dalam manajemen. Hal ini terjadi karena fungsi sumber daya manusia merupakan fungsi yang penting, Karen memegang aktivitas organisasi. Menurut para peneliti, asset sumber daya manusia dapat menjadi sumber keunggulan kompetitif yang berkelanjutan karena asset-aset manusia tersebut mempunyai penghetahuan dan kompleksitas social yang sulit ditiru oleh para pesaing. Praktek-praktek sumber daya manusia dapat menjadi sumber keunggulan kompetitif yang berkelanjutan antara lain, selektivitas dalam rekrutmen, pemberian upah yang memadai, pembagian informasi, keterlibatan dan pemberdayaan, pelatihan dan pengembangan, maupun keadilan keorganisasian.

Beberapa penelitian telah dilakukan oleh para praktisi maupun akademisi, terkait dengan kepemimpinan dan perannya dalam mempengaruhi tingkat komitmen karyawan. Menurut (Tsai, Tsai, \& Wang, 2011) dalam penelitiannya yang berjudul "A study on the relationship between leadership style, emotional intelligence, self-efficacy and organizational commitment : A case study of the Banking Industry in Taiwan", yang bertujuan menganalisis dengan metode penelitian kuantitatif untuk mengetahui dampak antara kecerdasan emosional dan gaya kepemimpinan, self-efficacy dan komitmen organisasi karyawan di industri perbankan di Taiwan. Studi ini menemukan bahwa emosional intelijen supervisor memiliki pengaruh positif signifikan terhadap gaya kepemimpinan, bahwa seorang supervisor dengan kecerdasan emosional yang tinggi mampu mengangkat self efficacy karyawan, kemudian self-efficacy karyawan berpengaruh signifikan positif terhadap komitmen organisasi.

Dalam penelitian (Chou, 2013; Gelaidan, 2011) membuktikan bahwa visi pimpinan berdampak pada tingkat komitmen karyawan pada organisasi tempat mereka bekerja. Kinerja bisnis sering berhubungan dengan komitmen karyawan yang mana di pertimbangkan sebagai prakondisi prilaku perusahaan. Beberapa faktor yang meningkatkan komitmen, visi pimpinan merupakan faktor sensitif dan faktor nilai yang menjadi pertimbangan oleh karyawan. Sebelumnya (Yaqoob, 2009) melakukan studi yang berkaitan dengan pengaruh dari Leadership Development pada kinerja karyawan, dengan lima factor dari Leadership Development yang mencakup pembelajaran (coaching), pelatihan dan pengembangan (training and development), pemberdayaan (empowerment), partisipasi (participation) dan pendelegasian (delegation). Dalam penelitian ini menemukan bahwa 50\% kinerja karyawan dipengaruhi oleh factor-faktor Leadership Development, sedangkan $50 \%$ faktor -faktor lainnya yang mempengaruhi kinerja karyawan.

Organisasi sebagai suatu tatanan birokrasi administratif atau suatu masyarakat insani (human community) yang hidup dan tumbuh kembang. Organisasi juga merupakan tempat mencari nafkah atau habitat untuk menumbuh kembangkan potensi insani dan wahana di mana orang mencari makna. Pandangan ini mengindikasikan adanya saling ketergantungan antara organisasi dan sumber daya manusia. Organisasi menjadi besar karena kompetensi dan prilaku yang karyawan yang memberikan kontribusi positif bagi kinerja organisasi. Sebaliknya organisasi secara manajerial juga harus memberikan kepuasan bagi karyawannya. Dari latar belakang masalah di atas, penulis tertarik untuk melakukan penelitian tentang "Peran Leadership Style, dan Job Satisfaction sebagai mediasi pada Organizational Commitment".

\subsection{Perumusan Masalah}

Banyak studi yang telah dilakukan dalam bidang psikologi dan manajemen yang menunjukkan pentingnya pemahaman tentang kepemimpinan, namun belum ditemukan studi yang meneliti tentang pengembangan kepemimpinan dan pengaruhnya pada komitmen afektif keorganisasian dengan 
dimediasi oleh Job Satisfaction, yang dilakukan di perusahaan milik daerah.

Penelitian ini mencoba menggali dan menguji keberadaan konstruk Job Satisfaction yang diproksikan dengan penilaian tingkat kepuasan kerja yang dirasakan dalam mempengaruhi komitmen afektif karyawan pada organisasi tempat mereka bekerja. Dengan demikian, setidaknya ada dua pertanyaan penelitian yang perlu dijawab dalam penelitian ini yaitu :

1) Apakah terdapat pengaruh Leadership Development terhadap job satisfaction?

2) Apakah terdapat pengaruh Empowering Leadership terhadap job satisfaction?

3) Apakah Job Satisfaction mampu berperan sebagai mediasi pengaruh Leadership Development dan Empowering Leadership terhadap Organizational Commitment?

\subsection{Tujuan Penelitian}

Penelitian ini tentang peran Leadership Development dan Empowering Leadership , dan pengaruhnya pada komitmen Organizational Commitment dengan dimediasi oleh job satisfaction bertujuan untuk :

1) Menginvestigasi dan memperoleh bukti empiris tentang pengaruh Leadership Development terhadap job satisfaction.

2) Menginvestigasi dan memperoleh bukti empiris tentang pengaruh Empowering Leadership terhadap job satisfaction.

3) Menginvestigasi dan memperoleh bukti empiris tentang peran variabel job satisfaction sebagai mediasi pengaruh Leadership Development dan Leadership Empowerment terhadap Organizational Commitment.

\subsection{Manfaat Penelitian}

Hasil penelitian ini diharapkan dapat memberikan kontribusi bagi pemahaman bagi praktisi maupun pengembangan penelitian yang berkaitan dengan Leadership Development dengan factor-faktor: pembelajaran (coaching), pelatihan dan pengembangan (training and development), pemberdayaan (empowerment), partisipasi (participation) dan pendelegasian (delegation), yang diharapkan dapat meningkatkan komitmen affektif karyawan pada organisasi di mana mereka bekerja.

Secara praktis, diharapkan dapat memberikan masukan dan memahami berbagai aspek perilaku karyawan terkait dengan kepemimpinan dan job satisfaction dan tingkat komitmen afektif karyawan dengan menelusuri faktor-faktor Leadership Development yang selanjutnya secara potensial dapat memberikan kegunaan bagi organisasi dan komitmen afektif karyawan pada organisasinya.

Temuan penelitian ini juga diharapkan dapat memperkaya pemahaman dan memberikan penjelasan mengenai keberadaan konstruk Job Satisfaction dan pola hubungannya dengan komitmen afektif karyawan.

\section{LANDASAN TEORI}

\subsection{Leadership Development}

Program Leadership Development bertujuan untuk meningkatkan ketrampilan manajer pada semua level pada bagian operasional, taktik, strategi dan penigkatan kepribadian yang lebih baik (Yaqoob, 2009). Adapun (Luthans \& Kyle., 2000) mengutarakan pendapatnya bahwa dimensi utama kepemimpinan yang efektif melibatkan, memperkuat dan memotivasi orang lain untuk mendorong kinerja yang unggul. Disamping itu imbalan keuangan dan nonkeuangan dapat dimanfaatkan untuk tujuan perusahaan.

Pentingnya pengakuan karyawan sebagai alat kepemimpinan yang efektif, sehingga karyawan harus diberikan perhatian lebih oleh para pemimpin karena mereka berusaha untuk memenuhi retensi dan produktivitas serta tantangan yang dihadapi organisasi saat ini. Masalah yang terus mengacaukan organisasi saat ini adalah memberatkan sumber daya keuangan dan manusia yang disebabkan oleh 
pergantian karyawan. Teori motivasi mendorong para pemimpin untuk mengikat hasil penting dari perilaku yang diinginkan. Untuk mempertahankan motivasi, pemimpin harus menunjukkan kepada karyawan hubungan erat antara kinerja dan penghargaan.

Untuk menerapkan kebijakan pengelolaan sumber daya manusia yang tepat, diperlukan seorang pemimpin yang memiliki kompetensi tinggi dan pengalaman yang cukup dalam mengelola karyawan. Kompetensi dan kemampuan seorang pemimpin perlu terus dikembangkan. Seorang pemimpin harus mampu memberdayakan, mendelegasikan tugas kepada bawahan, sekaligus melatih dan meningkatkan partisipasi karyawan untuk meraih tujuan organisasi.

\subsection{Empowering Leadership}

Menurut (Byham \& Cox, 1988) pemberdayaan didefinisikan sebagai membantu karyawan untuk mengambil tindakan secara mandiri terkait dengan pekerjaannya. Seorang pemimpin harus mampu memberdayakan bawahannya, sebagaimana seorang pemimipin harus mendapatkan pekerjaan yang dilakukan melalui standar kualitas tinggi, mendapatkan pekerjaan yang dilakukan melalui orang secara efisien dan efektif. Dalam meraih hasil kerja yang berkualitas, kepuasan kerja dan komitmen organisasi karyawan harus diperhatikan.

Menariknya, pemimpin yang sukses menghabiskan sebagian besar waktunya untuk berinteraksi dengan anak buahnya. Kemudian, pemimpin yang efektif memberikan hasil yang berkualitas melalui karyawan yang memiliki kepuasan kerja dan berkomitmen yang tinggi. Pemimpin yang efektif mengelola sumber daya manusia melalui memotivasi dan memperkuat perilaku dan meningkatkan nilai-nilai mereka dengan berkomunikasi dengan anak buah (karyawan) secara teratur.

Menurut (Abdollahi, Naveh Ibrahim, 2011) dalam (Hossein, Saleh, Iman, \& Jaafar, 2012) tantangan utama dalam mengelola sumber daya manusia adalah tantangan untuk meningkatkan pengetahuan sumber daya manusia. Pentingnya Sumber Daya Manusia sebagai faktor yang paling signifikan dalam rantai aktivitas setiap organisasi telah terbukti sejak lama dan organisasi telah memperhatikan masalah ini, dan telah membuat prioritas untuk meningkatkan kinerja mereka.

\subsection{Kepuasan Kerja}

Kepuasan kerja merupakan salah satu studi yang secara luas dipelajari dan digunakan sebagai konstruk pengukuran dalam penelitian perilaku keorganisasian dan literatur manajemen. Pemahaman tentang konsep kepuasan kerja membantu para peneliti bidang keprilakuan untuk memahami efek dari konsep ini yaitu misalnya komitmen organisasional, penilaian kinerja maupun intensitas turnover. Pentingnya pemahaman tentang konsep kepuasan kerja dipertegas oleh (Narang \& Dwivedi, 2010) mengatakan bahwa kepuasan kerja merupakan salah satu faktor penting yang mempengaruhi kepuasan hidup karena sebagian besar waktu manusia dihabiskan di tempat kerja.

Secara teoritis kepuasan kerja meliputi komponen evaluasi dan harapan. Misalnya, (Ismail, Yao, \& Yunus, 2009) mendefinisikan kepuasan kerja sebagai suatu sikap umum seorang individu terhadap pekerjaannya. Mirip dengan pernyataan di atas, (Greenberg, 1990) mengatakan bahwa orang akan merespon secara cepat tentang perasaannya baik positif maupun negatif terhadap pekerjaan yang sedang dan sudah dilakukan melalui berbagai macam pandangan maupun sikap yang ditunjukkan sebagai respon atas perasaannya. Menurut Baron dan Greenberg, berbagai macam pandangan dan sikap terhadap pekerjaan tersebut dinamakan kepuasan kerja. Dan secara spesifik Locke (1976) dalam (Parker \& Kohlmeyer, 2005) mendefinisikan kepuasan kerja sebagai pernyataan emosi yang menyenangkan yang berasal dari penilaian seseorang atas pekerjaannya atau pengalaman kerjanya. 
Maslow (1943) dalam (Baron dan Greenberg, 1990) mengatakan bahwa semua manusia setidaknya mempunyai lima hirarki kebutuhan yaitu kebutuhan fisikal (physiological needs), keamanan (safety needs), sosial (social needs), penghargaan (esteem needs) dan aktualisasi diri (self actualization). Menurut (Greenberg, 1990) dengan Teori Motivasi-Higiene (MotivationHygiene Theory) mengemukakan bahwa ada dua faktor yang mempengaruhi kepuasan dan ketidak puasan individu terhadap pekerjaan yatu instrinsik dan ekstrinsik. Menurut Herzberg, faktor-faktor intrinsik seperti kesempatan karyawan untuk mencapai prestasi individu, pengakuan oleh supervisor, kerja itu sendiri dan pertumbuhan berkaitan dengan kepuasan kerja. Sebaliknya, faktor-faktor ekstrinsik seperti kebijakan perusahaan, admininistrasi, supervisi, dan kondisi pekerjaan berkaitan dengan ketidakpuasan.

\subsection{Komitmen Organisasi (Organizational Commitment)}

Komitmen organisasi sebagai jasa identifikasi (kepercayaan terhadap nilai-nilai organisasi), keterlibatan (kesediaan untuk berusaha sebaik mungkin demi kepentingan organisasi) dan loyalitas (keinginan untuk tetap menjadi anggota organisasi yang bersangkutan) yang dinyatakan oleh seorang karyawan terhadap perusahaannya, komitmen organisasi merupakan kondisi dimana karyawan sangat tertarik terhadap tujuan, nilai-nilai, dan sasaran organisasinya. Menurut (Meyer, Stanley, Herscovitch, \& Topolnytsky, 2002), tiga dimensi komitmen organisasi adalah :

a. Komitmen afektif (affective commitment): keterikatan emosional karyawan dan keterlibatan dalam organisasi.

b. Komitmen berkelanjutan ( continouence commitment): komitmen berdasarkan kerugian yang berhubungan dengan keluarnya karyawan dari organisasi. Hal ini mungkin karena kehilangan senioritas atas promosi atau benefit.

c. Komitmen normaif ( normative commitment): perasaan wajib untuk tetap berada dalam organisasi karena memang harus begitu; tindakan tersebut merupakan hal benar yang harus dilakukan.

Dessler memberikan pedoman khusus untuk mengimplementasikan sistem manajemen yang mungkin membantu memecahkan masalah dan meningkatkan komitmen organisasi pada diri karyawan :

1. Berkomitmen pada nilai manusia: membuat aturan tertulis, memperkerjakan manajer yang baik dan tepat, dan mempertahankan komunikasi.

2. Memperjelas dan mengkomunikasikan misi organisasi: memperjelas misi dan ideologi; berkharisma; menggunakan praktik perekrutan bertdasarkan nilai; menekankan orientasi berdasarkan nilai dan pelatihan; membentuk tradisi,

3. Menjamin keadilan organisasi: memiliki prosedur penyampaian keluhan yang komprehensif; menyediakan komunikasi dua arah yang ekstensif,

4. Menciptakan rasa komunitas: membangun homogenitas berdasarkan nilai; keadilan; menekankan kerja sama, saling mendukung, dan kerja tim, berkumpul bersama,

5. Mendukung perkembangan karyawan: melakukan aktualisasi; memberikan pekerjaan menantang pada tahun pertama; memajukan dan memberdayakan; mempromosikan dari dalam; menyediakan aktifitas perkembangan; menyediakan keamanan kepada karyawan tanpa jaminan.

Komitmen keorganisasian menggambarkan sejauh mana ketertarikan emosional karyawan pada organisasi (H. K. Tjahjono, 2008). Pengukuran dikembangkan (Meyer et al., 2002) selanjutnya dimodifikasi terdiri atas 6 item pertanyaan, dengan menggunakan 5 poin skala likert. Kuesioner ini diadopsi dari Heru 


\section{JURNAL MANAJEMEN VOL. 6 N0. 1 JUNI 2016}

Kurnianto Tjahjono (2006). Indikator dari variabel ini adalah:
a. Karyawan merasa bahagia menjalani karirnya.
b. Karyawan merasa bahwa permasalahan yang dihadapi perusahaan juga merupakan permasalahan karyawan.

\subsection{Research Design}

Berdasarkan latar belakang dan hasil pengamatan di tempat penelitian dan data-data c. Karyawan memiliki rasa kepemilikan yang kuat pada tempat kerja.

d. Secara emosional, karyawan memiliki ikatan perasaan dengan tempat kerja.

e. Karyawan merasa sebagai bagian keluarga dari tempat kerja.

f. Karyawan merasa memiliki makna pribadi di kantor mereka bekerja.

yang peneliti peroleh maka dapat ditarik kerangka pemikiran sebagai berikut:

\section{$\underline{\text { Kerangka Berpikhir }}$}

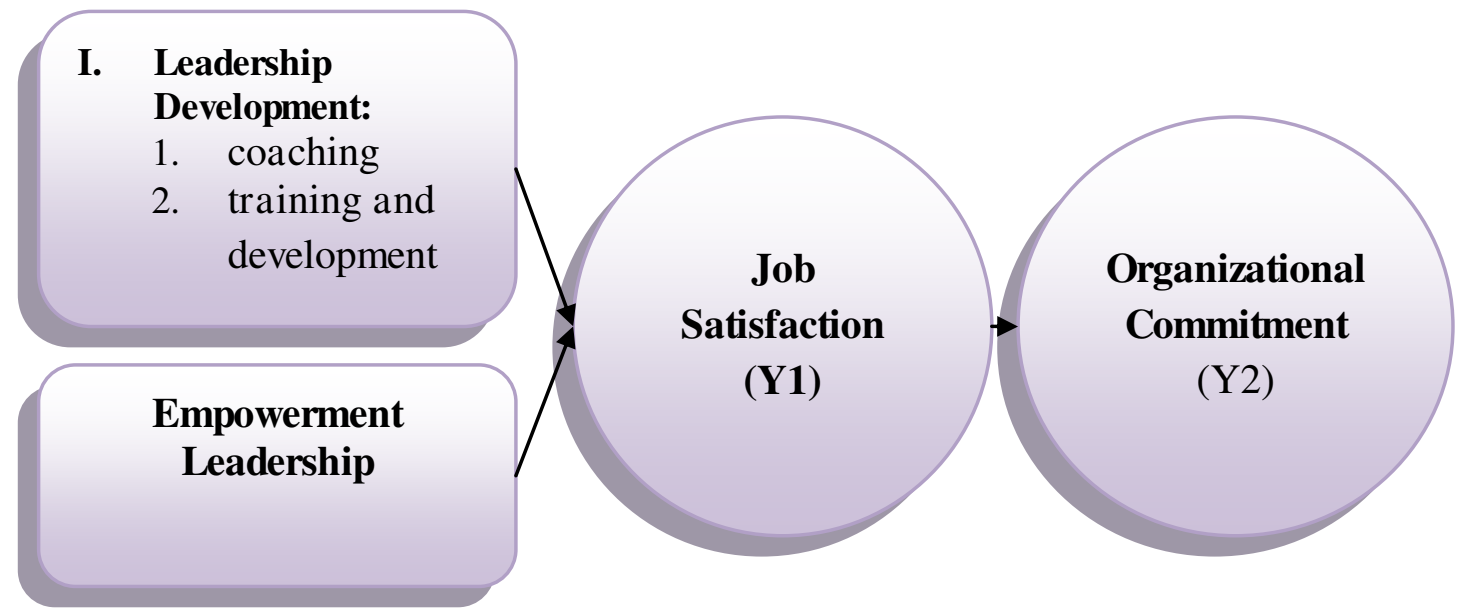

Gambar 1 Kerangka Berpikhir

\subsection{Hipotesis}

Hipotesis merupakan hal yang paling dalam suatu penelitian ilmiah, dimana hipotesis merupakan suatu petunjuk yang akan mempermudah penulis dalam mengumpulkan data. Hipotesis merupakan jawaban sementara terhadap rumusan masalah penelitian. Dikatakan sementara karena jawaban yang diberikan baru didasari teori yang relevan belum didasari atas fakta-fakta empiris yang diperoleh dari pengumpulan data. Adapun hipotesis dalam penelitian ini, antara lain :

\subsection{Leadership Development dan Satisfaction}

Pembelajaran dapat digunakan dalam pekerjaan untuk mengidentifikasi permasalahan seputar karyawan/pegawai, atau merupakan alat yang bisa digunakan untuk memecahkan permasalahan yang dihadapi oleh karyawan. (Champathes, 2006) selain itu pembelajaran merupakan teknik yang penting untuk meningkatkan kinerja. Pembelajaran akan terjadi interaksi dua arah di mana pelatih mengidentifikasi apa-apa yang dapat dikembangkan dan bagaimana cara mengembangkannya. Lebih jauh pemebelajaran dutujukan " beliefs and behaviors that hinder performance" (Toit, 2007). Pembelajaran dapat ditinjau lebih jauh, bahwa pembelajaran adalah Job segala sesuatu tentang bagaimana membantu seseorang untuk meningkatkan kinerjanya (Starr, 2004). 
Pelatihan dan pengembangan didesain untuk meningkatkan ketrampilan karyawan sehingga akan lebih baik. Peningkatan ketrampilan dapat dilakukan dengan memformalkan kebijakan pelatihan dan pengembangan karyawan. Pelatihan dan pengembangan diupayakan dapat meningkatkat kepuasan kerja dan komitmen karyawan pada organisasi di mana mereka bekerja. Lebih jauh organisasi harus mengisi kesenjangan antara pencapaian kinerja dengan kinerja yang diharapka oleh organisasi (Sahinidis, 2008).

Dengan demikian dapat ditarik suatu hipotesis :

H1 : Ada pengaruh positif signifikan antara leadership development pada Job Satisfaction.

\subsubsection{Empowering Leadership dan Job Satisfaction}

Menurut (Duvall, 1999) sukses sebagai pencapaian, prestasi dan pencapaian yang merupakan konsekuensi dari pemberdayaan. Dia mengungkapkan konsekuensi ini dalam bentuk keberhasilan melalui pemberdayaan sebagai (1) keberhasilan individu dalam bentuk kinerja peran karyawan, (March 2008) keberhasilan organisasi yang dicapai sebagai anggota organisasi dalam mencapai tujuan organisasi secara kolektif, dan (3) anggota dalam organisasi berbagi pengalaman kerja yang saling menguntungkan dan memuaskan untuk memenuhi kebutuhan pertumbuhan baik sosial dan pribadi. Selanjutnya (Bartram, 2007)

\section{METODE PENELITIAN}

\subsection{Obyek /Subyek Penelitian}

Penelitian ini dilakukan di Kantor Disperindagkop kabupaten Sleman. Sedangkan obyek penelitian ini adalah karyawan di Kantor Disperindagkop kabupaten Sleman.

\subsection{Populasi dan Sampel}

Responden penelitian ini dipilih karyawan yang memiliki kualifikasi dan pengalaman yang cukup. Oleh karena itu teknik convenience mengungkapkan dalam penelitiannya bahwa pemberdayaan memiliki korelasi positif yang signifikan dengan kinerja dan kepuasan. Berdasarkan beberapa penelitian di atas maka diusulkan hipotesis berikut :

H 2: Ada hubungan positif antara Leadership Development terhadap Job Satisfaction.

\subsubsection{Job Satisfaction dan Organizational Commitment}

Banyak cara yang dilakukan oleh kalangan praktisi untuk meningkatkan komitmen karyawan terhadap organisasinya. Karena para praktisi menyadari bahwa komitmen karyawan yang tinggi mampu meningkatkan kinerja organisasi, seperti penelitian yang dilakukan oleh (Meyer et al., 2002), kemudian (Hafer \& Martin, 2006) komitmen mampu meningkatkan mobilitas karyawan yang akan member kontribusi positif bagi organisasi.

Terkait dengan peran kepuasan kerja yang mampu meningkatkan komitmen organisasi dilakukan oleh (Bakhshi, Kumar, \& Rani, 2009). Bakhshi, Kumar, \& Rani, (2009) membuktikan secara empiris bahwa komitmen organisasi secara signifikan positif dipengaruhi oleh kepuasan kerja. Dari beberapa penelitian yang telah diuraikan di atas, maka ditarik hipotesis (H4) sebagai berikut:

H3: Ada hubungan positif antara Job Satisfaction dengan Organizational Commitment

sampling digunakan dalam penelitian ini. Data dikumpulkan selama dua bulan dengan jumlah kuesioner yang disebar sebanyak 200 buah.

\subsection{Jenis Data Penelitian}

Data yang digunakan dalam penelitian ini adalah data primer yang merupakan data yang diperoleh langsung dari responden melalui pengisian kuesioner yang diberikan pada responden yang berkaitan dengan variasi penelitian ini. Sumber data primer misalnya individu, focus group, panel responden yang 
khusus dibentuk oleh peneliti. Penelitian yang bersifat survey sering menggunakan wawancara, kuesioner, atau observasi orang dan fenomena (Tjahjono, 2009).

\subsection{Teknik Pengumpulan Data}

Pengumpulan data dilakukan dengan metode survey yaitu metode pengumpulan data primer dengan memberikan pertanyaan kepada responden individu. Data diperoleh dengan kuesioner yang dibagikan secara langsung kepada karyawan, yang memuat pertanyaan yang berkaitan dengan Leadership Development, Job Satisfaction, dan Organizational Commitment.

\subsection{Pengukuran Variabel}

Untuk mengukur Variabel eksogen Leadership Development dan Empowering Leadership, masing-masing jawaban adalah : Sangat Tidak Setuju (skor 1), Tidak Setuju (skor 2), Netral (skor 3), Setuju (skor 4), Sangat Setuju (skor 5,). Untuk mengukur variable endogen yaitu, Job satisfaction dan Organizational Commitment adalah : Sangat Tidak Setuju (skor 1) Tidak Setuju (skor 2), Netral (skor 3), Setuju (skor 4), Sangat Setuju (skor 5).

\subsection{Metode Uji Instrumen Penelitian}

Metode pengujian instrument dimaksudkan untuk menguji validitas dan reliabilitas kuesioner yang akan digunakan dalam penelitian sehingga dapat diketahui sampai sejauh mana kuesioner dapat menjadi alat pengukur yang valid dan reliabel dalam mengukur suatu gejala yang ada (Tjahjono, 2009).

\subsubsection{Uji Validitas}

Validitas menunjukkan sejauh mana suatu alat pengukur dapat mengukur apa yang ingin diukur (Sekaran, 2000). Instrumen yang dipakai dalam penelitian ini adalah kuesioner atau daftar pertanyaan. Ada syarat penting yang berlaku pada sebuah kuesioner yaitu keharusan sebuah kuesioner untuk sahih dan handal. Pengujian dimulai dengan menguji validitas terlebih dahulu baru diikuti oleh uji reliabilitas, jadi jika ada sebuah butir yang tidak sahih maka otomatis dibuang. Butir-butir yang sudah sahih kemudian baru secara bersama-sama diukur reliabilitasnya, untuk mengetahui keandalan kuesioner tersebut.

Validitas menguji seberapa baik instrument yang dikembangkan dalam mengukur konsep tertentu (Tjahjono, 2009) Pengujian validitas dilakukan untuk menunjukan sejauh mana suatu alat ukur mengukur apa yang diukur atau dengan kata lain apakah alat ukur tersebut telah tepat untuk mengukur obyek yang diteliti. Uji validitas dilakukan dengan menggunakan korelasi product moment dengan taraf signifikansi kurang dari $5 \%$.

\subsubsection{Uji Reliabilitas}

Reliabilitas mencerminkan konsistensi dan stabilitas. Konsistensi mengindikasikan seberapa bagus item-item dalam mengukur sebuah konsep. Cronbach's Alpha merupakan koefisien reliabilitas yang mengindikasikan seberapa bagus item-item terkorelasi secara positif antara yang satu dengan yang lain. Apabila Cronbach's Alpha semakin mendekati angka 1, maka semakin tinggi pula reliabilitas konsistensi internal (Tjahjono, 2009).

\subsection{Uji Hipotesis dan Analisis Data}

Setelah data dilakukan uji validitas, reliabilitas dan uji normalitas, maka data yang sudah memenuhi syarat tersebut dapat dilakukan analisis terkait dengan hipotesis yang diajukan dalam penelitian ini. Penelitian ini adalah penelitian kuantitatif.

\subsubsection{Analisis Kuantitatif}

Yaitu menganalisis data yang berbentuk angka atau data kualitatif yang diangkakan. Data kualitatif yang diangkakan (scoring) misalnya terdapat dalam skala pengukuran. Data kuantitatif yang berwujud angka-angka sebenarnya merupakan bahan dasar setiap penelitian yang bersifat statistik.

\subsubsection{Metode Analisis Data}


Penelitian ini menggunakan metode analisis Structural Equation Models (SEM). Metode ini telah berkembang menjadi metodologi yang sering digunakan dalam menyelidiki kebenaran hipotesis yang mengandung unsur hubungan sebab akibat secara struktural yang diturunkan dari teori (theory-derived structural/causal hypotheses).

\section{UJI KUALITAS DATA}

\subsection{Validitas}

Untuk memastikan bahwa data yang digunakan dalam penelitian ini berkualitas, maka
Metode SEM dilakukan dalam dua tahap utama, yaitu: (a) estimasi terhadap model yang diukur (measuring model), dan (b) estimasi terhadap model struktural (Ghozali, 2013). Dalam proses estimasi terhadap model yang diukur, peneliti akan menguji kecocokan skala yang diusulkan (proposed scales) dengan menggunakan tiga kriteria, yakni unidimensionality, reliability dan validity.

dilakukan uji validitas. Hasil pengujian validitas data dapat dilihat pada tabel 1 berikut:

Table 1 Standardized Regression Weights: (Group number 1 - Default model)

$\begin{array}{llll}\text { JP } & <--- & \text { LD } & .42662 \\ \text { JP } & <--- & \text { LEM } & .44531 \\ \text { COM } & <--- & \text { JP } & .90981 \\ \text { x3 } & <--- & \text { LEM } & .89288 \\ \text { x2 } & <--- & \text { LEM } & .83422 \\ \text { y1 } & <--- & \text { LD } & .92243 \\ \text { y3 } & <--- & \text { LD } & .67826 \\ \text { y11 } & <--- & \text { JP } & .90718 \\ \text { y12 } & <--- & \text { JP } & .80725 \\ \text { y9 } & <--- & \text { COM } & .90328 \\ \text { y8 } & <--- & \text { COM } & .91095 \\ \text { Y7 } & <--- & \text { COM } & .86715\end{array}$

Dari table 1 Standardized Regression Weights: (Group number 1 - Default model), hanya menunjukan beberapa indicator dari masing-masing variabel yang valid sehingga dilanjutkan ke langkah berikutnya yaitu, uji reliabilitas.

\subsection{Reliabilitas}

Setelah data diuji validitasnya, dimana variabelvariabel yang memiliki indikator-indikator yang valid dilanjutkan untuk uji reliabilitas. Untuk menguji reliabilitas, digunakan program SPSS 17. Hasil pengujian reliabilitas dapat dilihat pada table 2 berikut: 
Table 2 Reliabilitas

\begin{tabular}{c|cl}
$\begin{array}{c}\text { Variabe } \\
1\end{array}$ & $\begin{array}{c}\text { Cronbach's } \\
\text { Alpha }\end{array}$ & Reliabilitas \\
\hline LEM & 0,85 & Reliabel \\
LD & 0,88 & Reliabel \\
JS & 0,85 & Reliabel \\
COM & 0,92 & Reliabel
\end{tabular}

Dari table 2 di atas menunjukan semua variabel reliable, sehingga dapat dilanjutkan ke langkah berikutnya.

\subsection{Goodness Of Fit}

Berikut disajikan table 3 Goodness -Of-Fit Indices, dengan soft ware AMOS, dengan alat analisis SEM 21.0.

Table 3 Goodness -Of-Fit Indices

$\begin{array}{lccc}\text { Goodness-af-fit Index } & \text { Cut-off Value } & \text { Value } & \begin{array}{c}\text { Keteranga } \\ \mathrm{n}\end{array} \\ \text { Chi-square } & \begin{array}{c}\text { Diharapkan kecil } \\ \geq 0,05\end{array} & 0,034 & \text { Marginal } \\ \text { Significance Probability } & \leq 0,08 & 0,065 & \text { Baik } \\ \text { RMSEA } & \geq 0,90 & 0,945 & \text { Baik } \\ \text { GFI } & \geq 0,90 & 0,893 & \text { Marginal } \\ \text { AGFI } & \leq 2,00 & 23 & \text { Baik } \\ \text { CMIN/ DF } & \geq 0,95 & 0,978 & \text { Baik } \\ \text { TLI } & \geq 0,95 & 0,986 & \text { Baik } \\ \text { CFI } & & & \end{array}$

Dari table 3 Goodness -Of-Fit Indices di atas menunjukan, sebagian besar data dalam kondisi fit. Sedangkan Significance Probability sebesar 0,034 dan AGFI sebesar 0,893, tidak begitu jauh di bawah yang dipersyaratkan. Namun sebagaian besar fit maka data layak untuk digunakan dalam penelitian.

\subsection{Pengujian Hipotesis}

Berikut disajikan dalam table 4 Regression Weights: (Group number 1 - Default model), hasil analisis dari hipotesis yang diajukan: 
Table 4 Regression Weights: (Group number 1 - Default model)

$\begin{array}{lllrrrr} & & & \text { Estimate } & \text { S.E. } & \text { C.R. } & \text { P Label } \\ \text { JP } & <--- & \text { LD } & .44127 & .15017 & 2.93847 & .00330 \text { par_5 } \\ \text { JP } & <--- & \text { LEM } & .44682 & .13858 & 3.22440 & .00126 \text { par_6 } \\ \text { COM } & <--- & \text { JP } & .82769 & .06628 & 12.48725 & * * * \text { par_8 }\end{array}$

Dari table 4 Regression Weights: (Group number 1 - Default model), menggambarkan hubungan sebab akibat dari variabel eksogen yaitu: Leadership Development dan Empowering Leadership. Kemudian variabel mediasi Job Satisfaction dan sebagai outcome dari penelitian ini adalah Organizational Commitment.

\section{KESIMPULAN}

Pada table 4 Regression Weights: (Group number 1 - Default model), dapat disimpulkan bahwa:

1) Leadership Development berpengaruh signifikan positif terhadap Job Satisfaction, artinya adalah jika Leadership Development meningkat maka Job Satisfaction akan meningkat.

2) Empowering Leadership berpengaruh signifikan positif terhadap Job Satisfaction, artinya adalah jika Empowering Leadership meningkat maka Job Satisfaction akan meningkat dan

3) Job Satisfaction berpengaruh signifikan positif terhadap Organizational Commitment, artinya adalah jika Job Satisfaction meningkat maka Organizational Commitment akan meningkat.

Hasil analisis penelitian ini mendukung semua hipotesis yang diajukan. Oleh karena itu hasil penelitian ini bisa menjadi acuan atau referensi bagi kalangan praktisi, ketika ingin meningkatkan komitmen organisasi pada karyawannya. Kepuasan kerja dan komitmen organisasi secara luas telah banyak dibuktikan perannya dalam meningkatkan kinerja

Hasil analisis menunjukkan pengaruh Leadership Development terhadap Job Satisfaction menunjukkan nilai C.R $=2.93847$, $\mathrm{P}=0.00330$, kemudian Empowering Leadership berpengaruh signifikan positif terhadap Job Satisfaction, yang dibuktikan dengan nilai C.R $=3.22440, \mathrm{P}=.00126$. Selanjutnya hipotesis tiga juga didukung oleh hasil analisis, dimana nilai C. $\mathrm{R}=12.48725$ dan nilai $\mathrm{P}=0,000$.

organisasi (Markos \& Sridevi, 2010\{Gil, 2005 \#393).

\section{DAFTAR PUSTAKA}

Bakhshi, A., Kumar, K., \& Rani, E. (2009). Organizational Justice Perceptions as Predictor of Job Satisfaction and Organization Commitment International Journal of Business and Management, 4(9), 145-154.

Bartram, T. a. G. C. (2007). The relationship between leadership and follower in-role performance and satisfaction with the leader: . Leadership and Organization Development Journal, Volume 28, No. 1(The mediating effects of empowerment and trust in the leader), pp. 4-19.

Byham, W. C., \& Cox, J. (1988). Zapp! The lightening of empowerment. Pittsburg: Development Dimensions International Press.

Champathes, M. R. (2006). Coaching for performance improvement:The coach model. Development and Learning in Organizations, 20,

No. 2, pp.17-18.

Chou, P. (2013). The Effect of Transformational Leadership on Follower's Affective 
Commitment to Change. World Journal of Social Sciences, 3(1), 38-52.

Duvall, C. K. (1999). Developing individual freedom to act empowerment in the knowledge organization. Participation and Empowerment. An International Journal, Volume 7, No. 8, pp. 204-212.

Gelaidan, H. A. a. H. M. (2011). Organisational Culture, Leadership Styles and Employee's Affective Commitment to Change. Journal of Organizational Management Studies.

Ghozali, I. (2013). Model Persamaan Struktural Badan Penerbit Universitas Diponegoro.

Greenberg, J. (1990). Organizational justice : yesterday, to day, and tomorrow. Journal of Management, 16 (2), 399-432

Hafer, J. C., \& Martin, T. N. (2006). Job Involvement or Affective Commitment: A Sensitivity Analysis Study of Apathetic Employee Mobility Institute of Behavioral and Applied Management, $1-18$.

Hossein, R. D., Saleh, P. A., Iman, A. m., \& Jaafar, A. (2012). An Analysis of the Empowerment level of Employees and It's Relation to Organizational Factors. International Journal of Business and Social Science, 3(15), 225-263.

Ismail, A., Yao, A., \& Yunus, N. K. Y. (2009). Relationship Between Occupational Stress and Job Satisfaction: An Empirical Study in Malaysia. The Romanian Economic Journal, XII(34), 3-29.

Kriemadis, T., \& Papaioannou, A. (2006). Empowerment methods and techniques for sport managers. International Journal of Business and Management, 1(1-2), 117-133.

Luthans, \& Kyle. (2000). Recognition: A Powerful, but often Overlooked, Leadership Tool to Improve Employee Performance. Journal of Leadership \& Organizational Studies, vol 7, 1.

March 2008, R. C. R., Naresh Kumar, Haslinda Abdullah, Goh Yeng Ling. (2008). Organizational Culture as a Root of
Performance Improvement: Research and Recommendations. Contemporary Management Research, 4(1), 43-56.

Markos, S., \& Sridevi, M. S. (2010). Employee Engagement: The Key to Improving Performance. International Journal of Business and Management, 5(12), 89-96.

Meyer, J. P., Stanley, D. J., Herscovitch, L., \& Topolnytsky, L. (2002). Affective, Continuance, and Normative Commitment to the Organization: A Meta-analysis of Antecedents, Correlates, and Consequences. Journal of Vocational Behavior, 61, 20-52

Narang, R., \& Dwivedi, A. (2010). Managing The Job Satisfaction Of Knowledge Workers: An Empirical Investigation Asia Pacific Journal of Business and Management, 1(1), 1-14.

Parker, R. J., \& Kohlmeyer, J. M. (2005). Organizational justice and turnover in public accountant firms. a research note. Accounting, Organizations, and Society, 30, 357-369

Sahinidis, A. G. a. J. B. (2008). Employee perceived training

effectiveness relationship to employee attitudes. Journal of European Industrial Training (Emerald Publishing Group), Volume 32, No. 1, pp. 63-76.

Sekaran, U. (2000). Research methods for business : a skill-building approach (3

ed.): John Wiley \& Sons., Inc.

Starr, J. (2004). The manager's role in coaching overcoming barriers to success. Development and Learning in Organizations, 18, No.2, 9-12.

Tjahjono. (2009). Metode Penelitian Bisnis 2.0

Tjahjono, H. K. (2008). Pengaruh Keadilan Keorganisasian dan Modal Sosial, (Vol. 1): UPFE UMY. .

Toit, A. D. (2007). Making sense through coaching. Journal of Management Development, Volume 26, No. 3, pp. 282-291.

Tsai, M.-T., Tsai, C.-L., \& Wang, Y.-C. (2011). A study on the relationship between leadership style, emotional intelligence, 


\section{JURNAL MANAJEMEN VOL. 6 N0. 1 JUNI 2016}

self-efficacy and organizational commitment : A case study of the Yaqoob, Q. A. a. S. (2009). Efect of Leadership Banking Industry in Taiwan. African Development on Employee Journal of Business Management, 5(13), Performance. Pakistan Economic and $5319-5329$ 